\title{
DATA REPOSITORY:
}

\section{Analytical methods}

(U-Th)/He age determinations were conducted on single apatite grains, typically with 2-3 single grain analyses per sample. Apatite grains were selected for analysis under isopropyl alcohol using a stereographic microscope. Selected grains were clear, euhedral, and free of inclusions and fractures (e.g. Farley, 2002; Ehlers and Farley, 2003; Fitzgerald et al., 2006). Selected grains were photographed and measured along three principle axes to determine the $\mathrm{F}_{\mathrm{T}}$ correction for each grain (Farely et al., 1996). Individual apatite grains were packed in $1 \mathrm{~mm} \mathrm{Nb}$ stents and heated at $1150^{\circ} \mathrm{C}$ for 15 minutes in a resistance furnace. The released radiogenic ${ }^{4} \mathrm{He}$ was spiked with a known volume of ${ }^{3} \mathrm{He}$, purified with getters, and analyzed with a Balzers quadrupole mass spectrometer at Lehigh University. Calibration shots of known volume and ${ }^{4} \mathrm{He} /{ }^{3} \mathrm{He}$ concentration were run prior to and following a series of analyses to assess the sensitivity of the mass spectrometer, which is checked by the ${ }^{3} \mathrm{He}$ spike added to each unknown. Internal shards of Durango fluorapatite standard were run in conjunction with unknowns and prepared and analyzed using the same techniques. Following degassing, the grain stents were extracted from the furnace and analyzed for U, Th, and Sm concentrations at the University of Arizona. Apatite grains were dissolved directly from the stent using dilute ( $20 \%)$ warm nitric acid, and spiked with ${ }^{233} \mathrm{U},{ }^{229} \mathrm{Th}$, and ${ }^{147} \mathrm{Sm}$ and analyzed by an Element2 HR-ICP-MS. Effective uranium (eU) concentrations (Shuster et al., 2006) are calculated using the volume from the geometric approximation of the grain from the $\mathrm{F}_{\mathrm{T}}$ correction to calculate a mass of the grain and the measured mass of the ${ }^{238} \mathrm{U}$ and ${ }^{232} \mathrm{Th}$ from the same grain.

The $\mathrm{F}_{\mathrm{T}}$ correction is calculated using the measured axes and either a cylindrical (including flattened cylinder), ellipsoidal (including sphere), or tetragonal prism geometry dependent upon which best approximates the shape of the grain. The tetragonal prism geometry can accommodate the sharp tips of some grain morphologies (e.g. zircon grains) that have been shown to improve the accuracy of the FT corrections (Hourigan et al., 2005). Instead of using the surface-to-volume ratio of an equivalent sphere to calculate the $\mathrm{F}_{\mathrm{T}}$ correction for a nonspherical grain (Meesters and Dunai, 2002), we used a Monte-Carlo method that causes decays of all alpha producing isotopes at random $\mathrm{x}, \mathrm{y}$, and $\mathrm{z}$ coordinates within the input geometric approximation of the grain. The new point created by the decay (the alpha particle's stopping point) is then determined to be in or out of the grain. This is then repeated for $10^{7}$ decays and the ratio of alphas that are "in" to the total number of alphas created is the $\mathrm{F}_{\mathrm{T}}$ correction for that grain geometry. 
TABLE DR1. AHe ANALYTICAL FT CORRECTION AND MEASUREMENTS

\begin{tabular}{|c|c|c|c|c|c|c|c|c|}
\hline $\begin{array}{c}\text { Sample } \\
\text { name }\end{array}$ & $\begin{array}{c}\text { Ft } \\
\text { correction }\end{array}$ & ${ }^{4} \mathrm{He}(\mathrm{mol})$ & U (ng) & Th (ng) & Sm (ng) & $\begin{array}{l}\text { Grain length } \\
\qquad(\mu \mathrm{m})\end{array}$ & $\begin{array}{c}\text { Grain width } \\
\quad 1(\mu \mathrm{m})\end{array}$ & $\begin{array}{c}\text { Grain width } 2 \\
(\mu \mathrm{m})\end{array}$ \\
\hline \multirow[t]{2}{*}{ GR-20 } & 0.838 & $9.84693 \mathrm{E}-15$ & 0.128 & 0.024 & 2.605 & 256.4 & 149.6 & 141.7 \\
\hline & 0.882 & $3.35345 \mathrm{E}-14$ & 0.337 & 0.054 & 7.487 & 364.7 & 198.9 & 197.1 \\
\hline \multirow[t]{3}{*}{ GR-19 } & 0.691 & $5.55415 \mathrm{E}-15$ & 0.077 & 0.006 & 1.101 & 187 & 72.2 & 65.5 \\
\hline & 0.821 & $2.92405 \mathrm{E}-15$ & 0.027 & 0.067 & 0.317 & 299.9 & 149.3 & 121.2 \\
\hline & 0.790 & $1.97881 \mathrm{E}-14$ & 0.137 & 0.422 & 1.879 & 246.6 & 115.1 & 115.1 \\
\hline \multirow{2}{*}{ GR-1 } & 0.787 & $1.35093 \mathrm{E}-14$ & 0.105 & 0.287 & 1.253 & 265.3 & 121.2 & 101.9 \\
\hline & 0.767 & $5.73883 \mathrm{E}-15$ & 0.036 & 0.092 & 1.432 & 180.2 & 109.2 & 101.3 \\
\hline \multirow[t]{3}{*}{ GR-28 } & 0.731 & $2.39219 \mathrm{E}-15$ & 0.028 & 0.043 & 0.646 & 164.3 & 88.7 & 86.9 \\
\hline & 0.667 & $4.43164 \mathrm{E}-14$ & 0.062 & 0.511 & 1.109 & 175.3 & 73.7 & 70.7 \\
\hline & 0.665 & $1.59861 \mathrm{E}-14$ & 0.068 & 0.039 & 1.287 & 140.5 & 80.8 & 57.2 \\
\hline \multirow[t]{3}{*}{ GR-2 } & 0.776 & $8.44411 \mathrm{E}-15$ & 0.054 & 0.023 & 0.842 & 197.7 & 108.3 & 99.4 \\
\hline & 0.660 & $2.45895 \mathrm{E}-14$ & 0.100 & 0.034 & 1.298 & 205.3 & 61.5 & 61.2 \\
\hline & 0.622 & $9.80365 \mathrm{E}-15$ & 0.044 & 0.018 & 0.500 & 138.3 & 57.5 & 56.9 \\
\hline \multirow[t]{3}{*}{ GR-26 } & 0.760 & $1.23 \mathrm{E}-14$ & 0.130 & 0.088 & 2.118 & 240.2 & 104 & 82.3 \\
\hline & 0.796 & $7.47349 \mathrm{E}-15$ & 0.074 & 0.047 & 2.112 & 234.7 & 108.9 & 114.4 \\
\hline & 0.811 & $7.41665 \mathrm{E}-15$ & 0.073 & 0.027 & 2.183 & 188.2 & 131.9 & 126.1 \\
\hline GR-22 & 0.807 & $7.7466 \mathrm{E}-15$ & 0.081 & 0.055 & 2.383 & 211.4 & 123.6 & 122.7 \\
\hline \multirow[t]{4}{*}{ GR-8 } & 0.798 & $7.01088 \mathrm{E}-15$ & 0.074 & 0.018 & 1.259 & 250.6 & 102.2 & 120.3 \\
\hline & 0.826 & $2.06344 \mathrm{E}-14$ & 0.097 & 0.078 & 1.786 & 226.1 & 142 & 138.6 \\
\hline & 0.787 & $7.40768 \mathrm{E}-15$ & 0.066 & 0.027 & 1.922 & 314.3 & 95.5 & 103.1 \\
\hline & 0.839 & $9.84693 \mathrm{E}-15$ & 0.128 & 0.024 & 2.605 & 256.4 & 149.6 & 141.7 \\
\hline
\end{tabular}

